2014;25(7):747-753.

5. Zhang F, Hamon D, Fang $Z$, et al. Value of a posterior electrocardiographic lead for localization of ventricular outflow tract arrhythmias: the V4/V8 ratio. JACC: Clinical Electrophysiology. 2017;3(7):678-686

\title{
ĐĂC ĐIỂM LÂM SÀNG, RỐI LOAN ĐÔNG MÁU CỦA NHIỄM KHUẨN HUYẾT SƠ SINH TAI TRUNG TÂM NHI KHOA BỆNH VIỆN TRUNG ƯO'NG THÁI NGUYÊN
}

\author{
Đỗ Thái Sơn ${ }^{1}$, Phạm Trung Kiên ${ }^{2}$, Trần Tuấn Anh ${ }^{1}$,
} Ngô Thị Kim Quế ${ }^{1}$, Khổng Thị Ngọc Mai ${ }^{3}$

\section{TÓM TẮT}

Mục tiêu: Mô tả đăc điểm lâm sàng, xét nghiệm rối loạn đông máu ở trẻ sơ sinh nhiễm khuẩn huyết tại Trung tâm Nhi khoa, Bệnh viện Trung ương Thái Nguyên. Phương pháp nghiên cứu: nghiên cứu mô tả tiến cứu 38 bệnh nhẩn nhiễm khuẩn huyết tại Trung tâm Nhi khoa. Kết quả: triệu chứng của nhiễm khuấn huyết hay gặp là khó thở $86,8 \%$, bú kém $84,2 \%$, có $34,2 \%$ trẻ có biểu hiện xuất huyết dưới da, chảy máu phổi $10,6 \%$. Số lượng tiểu câuu giảm chiếm $55,3 \%$ trường hợp; tỉ lệ prothrombin giảm chiếm $44,7 \%$, thời gian Thromboplastin từng phần hoạt hoá (APTT) kéo dài chiếm 34,2\% và fibrinogen giảm chiếm 34,2\%. Kết luận: các biểu hiện lâm sàng của nhiễm khuẩn huyết ở trẻ sơ sinh hay găp là các dấu hiêu khó thở, bú kém. Các rối loạn đông cầm máu là giảm số lượng tiểu cầu, tỉ lê prothorombin giảm, APTT kéo dài.

Tư khóa: Rối loạn đông máu, nhiễm khuẩn huyết, sơ sinh, cây máu

\section{SUMMARY}

CLINICAL CHARACTERISTICS OF

COAGULATION DISORDERS OF NEONATAL

SEPSIS AT THAI NGUYEN NATIONAL HOSPITAL'S PEDIATRIC CENTER

Objectives: Description of clinical features and coagulation disorders in neonates infected by sepsis at Thai Nguyen National hospital's Pediatric center. Methods: across-sectional descriptive study. Results: Common clinical symptoms of sepsis are difficult breathing $86.8 \%$, poor feeding $84.2 \%$, mainly $34.2 \%$ of them are subcutaneous bleeding, followed by pulmonary bleeding with $10.6 \%$. The decrease in platelet count accounted for $55.3 \%$ of cases, the rate of Prothrombin decreased by $44.7 \%$, activated partial thromboplastin time (APTT) was prolonged by $34.2 \%$ and decreased fibrinogen accounted for $34.2 \%$. Conclusions: The most common clinical

${ }^{1}$ Trường Đại học Y-Dược, Đại học Thái Nguyên

${ }^{2}$ Trường Đại học Y Dược, Đại học Quốc gia Hà Nội

${ }^{3}$ Trường Đại học Đại Nam

Chiu trách nhiệm chính: Đỗ Thái Sơn

Email: dothaison@tnmc.edu.vn

Ngày nhận bài: 8.9.2021

Ngày phản biện khoa học: 25.10.2021

Ngày duyệt bài: 10.11.2021 manifestations of neonatal sepsis are difficulty breathing, and poor feeding. The coagulation disorders are decreased platelet count, decreased prothrombin ratio, extended APTT.

Keywords: coagulation, sepsis, neonates, blood culture.

\section{I. ĐẶT VẤN ĐỀ}

Nhiễm khuẩn huyết sơ sinh là nhiễm trùng toàn thân nặng, bệnh không chỉ gây tử vong hàng đâu ở cả trẻ sơ sinh đủ tháng và non tháng, mà còn để lại những di chứng nặng nê. Nhiễm trùng huyết là một biểu hiện đáp ứng của cơ thể với nhiễm trùng, gây ra hẩu hết các triệu chứng của nhiễm khuẩn huyết. Chẩn đoán sớm nhiễm khuẩn huyết ở trẻ sơ sinh không dễ dàng vì biểu hiện lâm sàng không đặc hiệu, các biểu hiện này rất đa dạng, tùy thuộc vào mức độ nghiêm trọng của nhiễm khuẩn huyết, nhanh chóng trở nên nặng nề,một trong những hậu quả là rối loạn đông máu và tổn thương các cớ quan. Bình thường hệ thống đông máu ở trạng thái cân bằng động, khi có tác động của nội độc tố, ngoại độc tố vi khuẩn vào hệ thống này thì đều có thể xẩy ra rối loạn đông máu, vì vậy rối loạn đông máu rất hay gặp ở trẻ sơ sinh nhiễm trùng huyết, các rối loạn này ở nhiều mức độ khác nhau từ nhẹ đến nặng, như đông máu nội quản rải rác, xuất huyết não. Tại Trung tâm Nhi khoa Bệnh viện Trung ương Thái Nguyên, hàng năm trẻ sơ sinh chiếm $23,5 \%$ số bệnh nhân vào viện điều trị, trong đó tỉ lệ trẻ nhiễm khuẩn huyết cao [4]. Vì vậy chúng tôi tiến hành nghiên này nhằm mục tiêu: Mô tả đặc điểm lâm sàng và xét nghiệm rôi loạn đông máu ở trẻ sơ sinh nhiễm khuẩn huyêt tại Trung tâm Nhi khoa Bệnh viện Trung ương Thái Nguyên.

II. ĐỐI TƯỢNG VÀ PHƯƠNG PHÁP NGHIÊN CỨU

2.1 Đối tượng nghiên cứu. Trẻ sơ sinh nhiễm khuẩn huyết điều trị tại Trung tâm Nhi khoa Bệnh viện Trung ương Thái Nguyên trong thời gian nghiên cứu. 
Tiêu chuẩn chọn bệnh nhân có hội chứng đáp ứng viêm kèm theo gợi ý hoặc có bằng chứng nhiễm trùng [8].

- Hội chứng đáp ứng viêm hệ thống khi có ít nhất 2/4 tiêu chuẩn sau (trong đó có một tiêu chuẩn phải có là bất thường nhiệt độ hay bạch cầu tăng): nhiệt độ $>38,5^{\circ} \mathrm{C}$ hoặc $<36^{\circ} \mathrm{C}$; bạch câu tăng hoặc giảm theo tuổi; nhịp tim tăng; nhịp thở tăng.

- Gợi ý hoặc có bằng chứng nhiễm trùng: cây máu dương tính, nhuộm soi tươi thây tác nhân gây bệnh, CRP> 10mg/l

\subsection{Phương pháp nghiên cứu}

2.2.1. Thiết kế nghiên cứu. Nghiên cứu mô tả

\subsubsection{Mẫu nghiên cứu}

- Cõ mẫu: áp dụng công thức tính cõ̃ mẫu cho nghiên cứu mô tả

$$
n=Z^{2}-a / 2 \frac{p \cdot q}{d^{2}}
$$

Trong đó:

+ n: là số đối tượng nghiên cứu.

+ p: tỉ lệ hạ thân nhiệt ở trẻ sơ sinh nhiễm khuẩn huyết theo nghiên cứu của Lê Thị Công Hoa tại Bệnh viện Trung Ương Huế là 1,8\% [2].

$+q=1-p ; d$ : sai số ước lượng, chọn $d=0,05$.

$+Z_{1}$ - a/2: hệ số giới hạn tin cậy $=1,96$ (với độ tin cậy 95\%).

Theo công thức, cỡ mẫu cần thiết là 28 trẻ.

- Chọn mấu: trong thời gian nghiên cứu chúng tôi chọn được 38 bệnh nhân có chẩn đoán nhiễm khuẩn huyết điều trị tại Trung tâm Nhi khoa, Bệnh viện Trung ương Thái Nguyên.

\subsubsection{Chỉ sốnghiên cứu:}

- Chỉ số chung: tỉ lệ trẻ theo tuổi thai, giới, cân nặng khi sinh, tuổi vào viện, cách thức sinh, hồi sức sau sinh.

- Các chỉ số lâm sàng: tỉ lệ trẻ hạ nhiệt độ, sốt, li bì, khó thở, nhịp tim nhanh, kích thích, giảm trương lực cơ, bú kém, bụng chướng, gan to, lách to, vàng da.

- Chỉ số cận lâm sàng: tỉ lệ trẻ giảm tiểu cầu, tỉ lệ trẻ giảm prothrombin, APTT kéo dài, Fibrinogen giảm.

\subsubsection{Thu thập và xứ lý số liệu}

- Thông tin bệnh nhân thu thập theo mẫu bệnh án nghiên cứu

- Khám lâm sàng do các bác sĩ chuyên khoa Nhi thực hiện. Xét nghiệm được tiến hành tại Trung tâm huyết học truyền máu, Bệnh viện Trung ương Thái Nguyên.

- Nhập liệu và xử lý số liệu theo phần mềm SPSS 16.0

\section{KẾT QUẢ NGHIÊN CỨU}

Bảng 2.1. Đặc điểm chung của nhóm nghiên cứlu

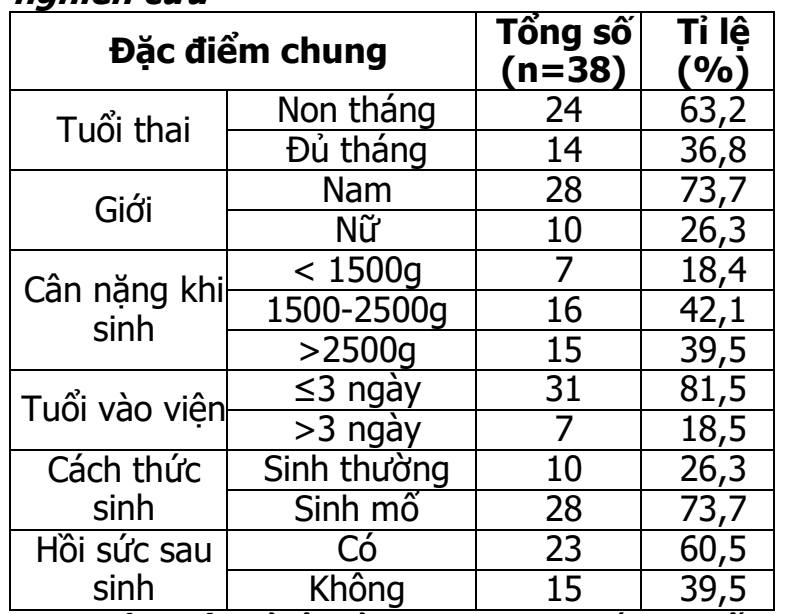

Nhận xét: Tỉ lệ trẻ sơ sinh non tháng chiếm $63,2 \%$, cân năng khi sinh dưới $2500 \mathrm{~g}$ chiếm tỉ lệ $60,5 \%$, tuổi vào viện $81,5 \%$ là $\leq 3$ ngày, $73,7 \%$ trẻ sinh mổ, 60,5\% trẻ phải hồi sức sau sinh.

Bảng 2.2. Đặc điểm lâm sàng trẻ sơ sinh nhiễm khuẩn huyêt

\begin{tabular}{|c|c|c|c|c|c|c|}
\hline \multirow{2}{*}{ Triệu chứng Tuối } & \multicolumn{2}{|c|}{ Non tháng } & \multicolumn{2}{c|}{ Đủ tháng } & \multicolumn{2}{c|}{ Tống } \\
\cline { 2 - 7 } & $\mathbf{n}$ & $\mathbf{\%}$ & $\mathbf{n}$ & $\mathbf{\%}$ & $\mathbf{n}$ & $\mathbf{\%}$ \\
\hline Hạ thân nhiệt & 3 & 7,9 & 0 & 0,0 & 3 & 7,9 \\
\hline Sốt & 14 & 36,8 & 9 & 23,7 & 23 & 60,5 \\
\hline Li bì & 13 & 34,2 & 7 & 18,4 & 20 & 52,6 \\
\hline Khó thớ & 19 & 50,0 & 14 & 36,8 & 33 & 86,8 \\
\hline Nhịp tim nhanh & 3 & 7,9 & 2 & 5,3 & 5 & 13,2 \\
\hline Kích thích & 1 & 2,6 & 1 & 2,6 & 2 & 5,2 \\
\hline Giảm trương lực cơ & 11 & 28,9 & 3 & 7,9 & 14 & 36,8 \\
\hline Bú kém & 20 & 52,6 & 12 & 31,6 & 32 & 84,2 \\
\hline Bụng chướng & 14 & 36,8 & 7 & 18,5 & 21 & 55,3 \\
\hline Gan to & 5 & 13,2 & 0 & 0,0 & 5 & 13,2 \\
\hline Lách to & 1 & 2,6 & 1 & 2,6 & 2 & 5,2 \\
\hline Vàng da & 14 & 36,8 & 10 & 26,4 & 24 & 63,2 \\
\hline
\end{tabular}

Nhận xét: Các triệu chứng lâm sàng hay gặp là khó thở 86,8\%, bú kém 84,2\%. 
Bảng 2.3. Vị trí xuất huyết ở trẻ sơ sinh nhiễm khuẩn huyết

\begin{tabular}{|c|c|c|c|c|c|c|}
\hline \multirow{2}{*}{ Vị trí xuất huyết Tuổi } & \multicolumn{2}{c|}{ Non tháng } & \multicolumn{2}{c|}{ Đủ tháng } & \multicolumn{2}{c|}{ Tổng } \\
\cline { 2 - 7 } & $\mathbf{n}$ & $\mathbf{\%}$ & $\mathbf{n}$ & $\mathbf{\%}$ & $\mathbf{n}$ & $\mathbf{\%}$ \\
\hline Có xuất huyết & 13 & 34,2 & 7 & 18,4 & 20 & 52,6 \\
\hline Dưới da & 9 & 23,7 & 4 & 10,5 & 13 & 34,2 \\
\hline Niêm mạc & 1 & 2,6 & 1 & 2,6 & 2 & 5,3 \\
\hline Chảy máu phối & 3 & 7,9 & 1 & 2,6 & 4 & 10,5 \\
\hline Xâ̂́t huyết não & 1 & 2,6 & 0 & 0,0 & 1 & 2,6 \\
\hline Xuất huyêtt tiêu hóa & 0 & 0,0 & 1 & 2,6 & 1 & 2,6 \\
\hline
\end{tabular}

Nhận xét: Có 20 bệnh nhân có dấu hiệu xuất huyết chiếm tỉ lệ 52,6\%, trong đó vị trí xuất huyết thường gặp là xuất huyết dưới da chiếm $34,2 \%$.

Bảng 2.4. Xét nghiệm tiểu cầu ở tré sơ sinh nhiếm khuẩn huyết

\begin{tabular}{|c|c|c|c|c|c|c|}
\hline \multirow{2}{*}{ Số lượng tiểu câu (G/I) } & \multicolumn{2}{c|}{ Nuối } & \multicolumn{2}{c|}{ Đủ tháng } & \multicolumn{2}{c|}{ Tổng } \\
\cline { 2 - 7 } & $\mathbf{n}$ & $\mathbf{\%}$ & $\mathbf{n}$ & $\mathbf{\%}$ & $\mathbf{n}$ & $\mathbf{\%}$ \\
\hline$<50$ & 1 & 2,6 & 2 & 5,3 & 3 & 7,9 \\
\hline $50-99$ & 7 & 18,4 & 1 & 2,6 & 8 & 21,1 \\
\hline $100-149$ & 6 & 15,8 & 4 & 10,5 & 10 & 26,3 \\
\hline$\geq 150$ & 10 & 26,3 & 7 & 18,4 & 17 & 44,7 \\
\hline
\end{tabular}

Nhận xét: Tỉ lệ trẻ có tiếu cầu giảm dưới $150 \mathrm{G} / \mathrm{l}$ chiếm $55,3 \%$, đặc biệt có 7,9\% số trẻ có giảm số lượng tiểu cầu mức độ nặng.

Bảng 2.5. Kết quả xét nghiệm đông máu trẻ sơ sinh nhiễm khuẩn huyêt

\begin{tabular}{|c|c|c|c|c|c|c|c|}
\hline \multirow{2}{*}{\multicolumn{2}{|c|}{ Đông máu Tuổi }} & \multicolumn{2}{|c|}{ Non tháng } & \multicolumn{2}{|c|}{ Đủ tháng } & \multicolumn{2}{|c|}{ Tổng } \\
\hline & & $\mathbf{n}$ & $\%$ & $\mathbf{n}$ & $\%$ & $\mathbf{n}$ & $\%$ \\
\hline \multirow{2}{*}{$\begin{array}{c}\text { Tỉ lệ prothrombin } \\
(\%)\end{array}$} & Bình thường & 14 & 36,8 & 7 & 18,4 & 21 & 55,3 \\
\hline & Giảm & 10 & 26,3 & 7 & 18,4 & 17 & 44,7 \\
\hline \multirow{2}{*}{ APTT (giây) } & Bình thường & 15 & 39,5 & 10 & 26,3 & 25 & 65,8 \\
\hline & Kéo dài & 9 & 23,7 & 4 & 10,5 & 13 & 34,2 \\
\hline \multirow{2}{*}{ Fibrinogen $(\mathrm{g} / \mathrm{l})$} & Bình thường & 15 & 39,5 & 10 & 26,3 & 25 & 65,8 \\
\hline & Giảm & 9 & 23,7 & 4 & 10,5 & 13 & 34,2 \\
\hline
\end{tabular}
$34,2 \%$.

Nhận xét: Tỉ lệ prothrombin giảm chiếm 44,7\%, APTT kéo dài chiếm 34,2\% và fibrinogen giảm là

\section{BÀN LUÂ̂N}

Nhiễm khuẩn huyết sơ sinh có những biểu hiện lâm sàng đa dạng và phong phú. Kết quả nghiên cứu của chúng tôi thây rằng, triệu chứng gặp nhiều là khó thở chiếm $86,8 \%$, vàng da chiếm $63,2 \%$, sốt chiếm $60,5 \%$ và bú kém chiếm $84,2 \%$. Kết quả nghiên cứu của chúng tôi phù hợp với nghiên cứu của Bùi Mẫn Nguyên khi mô tả đặc điểm lâm sàng của 42 trẻ được chẩn đoán nhiễm trùng huyết có cấy máu dương tính biểu hiện khó thở chiếm $76,2 \%$, sốt chiếm $33,3 \%$ và vàng da chiếm 45,2\% [5]. Nghiên cứu của Trần Thị Chuyên trên 44 trẻ bị nhiễm khuẩn huyết, kết quả có $81 \%$ bệnh nhân có khó thở [1]. Nghiên cứu của Ying Fan tại Trung Quốc tî lệ bệnh nhân nhiễm khuẩn huyết có khó thở còn chiếm đến 96,5\% [6]. Sở dĩ kết quả nghiên cứu của Ying Fan có tî lệ cao hơn nghiên cứu của chúng tôi là do nghiên cứu này trên những bệnh nhân nhiễm khuẩn huyết đang nằm tại khoa hồi sức tích cực, các triệu chứng đều rất nặng và rầm rộ.
Xuất huyết cũng là một biểu hiện thường thấy trong nhiễm khuẩn huyểt sơ sinh, khi vi khuẩn xâm nhập vào máu gây rối loạn đông máu, làm các dấu hiệu xuất huyết bắt đầu xuất hiện, kết quả nghiên cứu của chúng tôi có $52,6 \%$ trẻ có biểu hiện xuất huyết, trong đó đa phần là xuất huyết dưới da chiếm $34,2 \%$. Nghiên cứu của Bùi Mẫn Nguyên phù hợp với kêt quả nghiên cứu của chúng tôi, cho thấy tỉ lê bênh nhân có biểu hiện xuất huyết chiếm $47,6 \%$, xuất huyết dưới da cũng chiếm đa số với tî̉ lệ là $35,7 \%$ [5].

ớ trẻ sơ sinh giảm tiểu câuu thường gây biến chứng nặng nề như xuất huyết não, Salem $\mathrm{N}$ nghiên cứu trên bệnh nhân nhiễm khuẩn huyết cho kết quả nếu tiểu cầu $<30 \mathrm{G} / \mathrm{l}$ là mối nguy hiểm thực sự đối với bệnh nhân xuất huyết nặng nề trên lâm sàng [7]. kết quả nghiên cứu của chúng tôi cho thấy có $55,3 \%$ trường hợp nhiê̂m khuẩn huyết có số lượng tiểu cầu giảm dưới 150 $\mathrm{G} / \mathrm{l}$, đặc biệt có $7,9 \%$ số trẻ có giảm số lượng tiểu cẩu mức độ nặng $<50 \mathrm{G} / \mathrm{l}$. Kết quả nghiên cứu của Võ Hữu Hội không có nhiều khác biệt so với nghiên cứu của chúng tôi, tỉ lệ trẻ có tiểu cầu 
giảm dưới $150 \mathrm{G} / \mathrm{l}$ là $30,8 \%$, tuy nhiên mức độ giảm số lượng tiểu câuu nặng là 10,8\% [3].

Tỉ lệ prothrombin giảm có khả năng là một chỉ điểm của nhiễm khuẩn huyết sơ sinh, kết quả nghiên cứu của chúng tôi có 17 trẻ có tî lệ prothrombin giảm chiếm $44,7 \%$ tương đương với nghiên cứu của Võ Hữu Hội tỉ lệ prothrombin giảm là $40 \%$. APTT là xét nghiệm cơ bản để đánh giá con đường đông máu nội sinh, nghiên cứu của chúng tôi có 13 trẻ APTT kéo dài chiếm tỉ lệ là $34,2 \%$, phù hợp với các nghiên cứu của Võ Hữu Hội 35,4\%. Fibrinogen là một protein huyết tương nồng độ cao trong máu, kích thước lớn dạng lỏng, có thể phân chia được, từ đó có thể tạo nên mạng lưới lớn của nút cầm máu, tình trạng giảm fibrinogen máu là đặc trưng cho tỉ lệ tử vong cao ở trẻ em nhiễm trùng huyết, nghiên cứu của Võ Hữu Hội có tỉ lệ fibrinogen giảm là 30,8\%[3], của Bùi Mẫn Nguyên 38,1\% [5]. Nghiên cứu của chúng tôi cũng chỉ ra rằng tî lệ fibrinogen giảm chiếm 34,2 \% phù hợp với kết quả của hai tác giả trên.

\section{KẾT LUÂN}

- Triệu chứng lâm sàng của nhiễm khuẩn huyết ở trẻ sơ sinh: khó thở $86,8 \%$; bú kém: $84,2 \% ; 34,2 \%$ có xuất huyết dưới da và $10,6 \%$ chảy máu phổi.

- Xét nghiệm: số lượng tiểu cầu giảm chiếm $55,3 \%$ trường hợp, $7,9 \%$ trường hợp có số lượng nặng < 50G/l. Tỉ lệ prothrombin giảm chiếm $44,7 \%$, APTT kéo dài chiếm $34,2 \%$ và fibrinogen giảm chiếm 34,2\%.

\section{TÀI LIÊU THAM KHẢO}

1. Trân Thị Chuyên (2011), "Nghiên cứu một số đăc điểm lâm sàng cân lâm sàng và rối loan đông cẩm máu ở trẻ sơ sinh nhiễm khuẩn huyết tại khoa sơ sinh Bệnh viện Nhi Trung ương", Luận văn tốt nghiệp bác sĩ Nội trú.

2. Lê Thi Công Hoa (2016), "Tình hình nhiễm khuẩn huyết tai bệnh viện ở trẻ sơ sinh bênh viên Trung Ương Hiuế năm 2014", Y Dược Thành Phố Hồ Chí Minh. phụ bản tập 20,5, tr. 77-84.

3. Võ Hữu Hội (2018), "Nghiên cứu đặc điểm lâm sàng và một số yếu tố rối loan đông máu ở bênh nhi Nhiêm khuẩn huyết tai Bểnh viên Phu Sản-Nhi Đà Nẵng", Tạp chí Y Dược học- Trường Đại học Y Dước Huế. tấp 8 tr. 97-103.

4. Nguyến Thị Xuân Hương (2012), "Tình hình bênh tât và tữ vong sơ sinh tai khoa Nhi Bênh viên Đa khoa Trung ương Thái Nguyên trong 3 năm (2008-2010)", Tạp chí khoa học công nghệ Đại học Thái Nguyên. tập 89 số 01/1, tr. 209-213.

5. Bùi Mấn Nguyên (2017), "Nghiên cứu rối loạn đông máu ở tré sơ sinh bị nhiếm khuẩn huyết tại bệnh viện trẻ em Hải Phòng", tạp chí nhi khoa. tập 10 , số 4 , tr. 39-45.

6. Fan $Y, Y u ~ J$, Astruc D (2012), "Clinical manifestations and treatment of early-onset neonatal sepsis: a Chinese-French comparison", Zhonghua Er Ke Za Zhi. 50(9), pp. 664-671.

7. Salem S.Y, Sheiner E, Zmora E et al (2006) "Risk factors for early neonatal sepsis", Arch Gynecol Obstet. 274(4), pp. 198-202.

8. Singer $M$, Deutschman $C$, Seymour $C$ et al (2016), "The Third International Consensus Definitions for Sepsis and Septic Shock (Sepsis-3)", JAMA. 315(8), pp. 801-810.

\section{HÌNH ẢNH CộNG HƯởNG TỪ CỦA BỆNH THOÁT VI MÀNG NÃ̃O TUỶ VÙNG CÙN G CỤT Ở TRẺ EM}

\section{TÓM TẮT}

Mục tiêu: Mô tả hình ảnh cộng hưởng từ (CHT) của bệnh thoát vị màng não tuỷ vùng cùng cụt ở trẻ em. Phương pháp nghiên cứu: Nghiên cứu mô tả cắt ngang, gồm 32 bệnh nhân được chẩn đoán và điều trị bệnh thoát vị màng não tuỷ vùng cùng cưt tại Trung tâm thần kinh - Bệnh viện Nhi Trung Ương,

\footnotetext{
${ }^{1}$ Trường Đại học Y Hà Nội, ${ }^{2}$ Bệnh viện Nhi Trung Uơng Chịu trách nhiệm chính: Đố Thanh Hương Email: dothanhhuong@hmu.edu.vn Ngày nhận bài: 10.9.2021 Ngày phản biên khoa họ: 1.11 .2021 Ngày duyệt bài: 12.11.2021
}

\section{${ }^{1} \boxplus$ ỗ Thanh Hương, ${ }^{1}$ Moeun My, ${ }^{2}$ Cao Vũ Hùng, ${ }^{2}$ Lê Nam Thắng, ${ }^{2}$ Lê Đình Công} trong thời gian 1 năm (từ ngày $01 / 07 / 2020$ đến 30/06/2021). Kết quả: 32 bênh nhân thỏa mãn các tiêu chuẩn lựa chọn. Tuổi trung bình khi nhập viện là $10,4 \pm 14,2$ tháng, trẻ nam mắc bệnh nhiều hợn trẻ nữ (tỷ lệ nam/nữ là 1,46/1). CHT cột sống vùng cùng cụt cho thấy khối thoát vị ở vùng xương cùng chiếm $59,4 \%$, vùng xương cụt chiếm 40,6\%. Chiều dài trung bình của khối thoát vị là $2,2 \pm 1,0 \mathrm{~cm}$. Chiều rộng trung bình của khối thoát vị là $2,3 \pm 1,4 \mathrm{~cm}$. Thành phân của khối thoát vị: $100 \%$ chứa dịch, $87,5 \%$ chứa tuỷ, $46,9 \%$ chứa mõ, $40,6 \%$ chứa rể thần kinh và $37,5 \%$ chứa các dây xơ. Phân bố các thể TVMNT: $46,9 \%$ thoát vị mõ - tủy - màng tủy; $40,6 \%$ thoát vị tủy - màng tủy và $12,5 \%$ thoát vị màng tủy. Hầu hết các bệnh nhân kèm tủy bám thấp với tỷ lê $96,9 \%$. Kết luân: $\mathrm{CHT}$ cột sống là phương pháp chẩn đoán hình ảnh có độ chính xác cao nhất trong chẩn đoán bệnh 